\section{Wie ist die Prognose bei „GIST“ im Darm? \\ Protein hemmt Kolonkarzinom}

Bei gastrointestinalen Stromatumoren (GIST) im Dünndarm gehen Experten bislang von einer schlechteren Prognose aus als bei gastrischen GIST. So wird bei Dünndarm-GIST nach der häufig verwendeten Klassifikation des US-amerikanischen Armed Forces Institute of Pathology ein höheres Risiko für Metastasen und Todesfälle attestiert, berichten Onkologen. Sie kommen nach einer aktuellen Auswertung der SEER-Datenbank mit Angaben zu rund $28 \%$ aller Krebspatienten in den USA jedoch zu einem anderen Schluss: Danach sind die Überlebenschancen für Patienten mit Dünndarm-GIST nicht schlechter als für solche mit Stromatumoren im Magen.

Guller U et al. Gastric Cancer 2017;20:49-60
Immunologen haben entdeckt, dass das Protein NLRC3 verhindert, dass sich Kolonzellen zu Krebszellen entwickeln. Wird das Protein deletiert, dann fördert dies die Entwicklung eines Kolonkarzinoms. Bekannt ist außerdem, dass Kolonkarzinome eine stark reduzierte NLRC3-Genexpression aufweisen. Auch molekulare Komponenten des tumorsupprimierenden Signalwegs konnten identifiziert werden. NLRC3 ist Teil einer Familie von NLR-Sensorproteinen, die Immunfunktionen und andere Zellfunktionen kontrollieren. Es reguliert bestimmte Moleküle und steuert Zellproliferation, Immunantwort, Entzündung und Krebsentwicklung.

Karki Ret al. Nature. 2016;540(7634):583-7

\section{Nur gereizt oder doch gravierend?}

Häufiges ist häufig, Seltenes ist selten: Zum Glück leiden die meisten Patienten mit Magen-Darm-Beschwerden nicht an einer ernsthaften Erkrankung, sondern z. B. am „Reizmagen" oder "Reizdarm". Um jedoch als behandelnder Arzt auf "Nummer Sicher" zu gehen und schwerwiegende Ursachen nicht zu übersehen, empfehlen Experten das Vorgehen nach einem diagnostischen Algorithmus. Welche Schritte dieser beinhaltet, lesen Sie im Schwerpunkt "Gastroenterologie".

Claudia Daniels Redakteurin

\title{
Einer von 14 Hausarztpatienten hat Darmkrebs in der Familie
}

Menschen mit positiver Familienanamnese für ein kolorektales Karzinom haben ein gegenüber der Allgemeinbevölkerung zwei- bis vierfach erhöhtes Risiko, selbst an Darmkrebs zu erkranken. In der Leitlinie zum Kolonkarzinom wird daher empfohlen, bei Angehörigen dieser Risikogruppe schon zehn Jahre vor dem Erkrankungsalter des Indexpatienten mit Screeningkoloskopien zu beginnen. Ein organisiertes Screening ist für diese Risikopersonen bislang jedoch nicht vorgese- hen. Damit den Betroffenen die Möglichkeit zur Früherkennung eröffnet wird, ist es wichtig, dass der Hausarzt eine Familienanamnese erhebt. Um einen Patienten mit familiärer Vorbelastung ausfindig zu machen, muss er durchschnittlich nur 14 Patienten im Alter von 40 bis 54 Jahren befragen. Das hat eine Studie in Deutschland ergeben, die Ärzte um Jasper Plath, Frankfurt, vorgelegt haben.

Plath J et al. Family Practice 2017;34(1):30-5

\section{Patienten mit Leberzirrhose profitieren von Krebs-Screening}

Forscher haben in einer retrospektiven Kohortenstudie nach Zusammenhängen zwischen HCC-Screening und der frühen Entdeckung des Lebertumors, einer kurativen Therapie und dem Gesamtüberleben bei Zirrhose-Patienten gesucht. Hierzu analysierten sie die Daten von Patienten, bei denen in der Zeit von 2012 bis 2013 ein HCC diagnostiziert worden war. Das Ergebnis: Bei 42\% der 374 im Mittel 60-jährigen Patienten mit HCC war der Tumor im Rahmen eines Screenings entdeckt worden.
Unter diesen Patienten fanden sich signifikant mehr Tumorfrühformen als bei den anderweitig diagnostizierten Tumoren und es bestand häufiger die Chance zu einer kurativen Therapie (30,6\% vs. 13.0\%). In der Analyse, in die demografische Faktoren, der Schweregrad der Leberzirrhose sowie die Leistungsfähigkeit des Patienten einflossen, zeigte sich bei gescreenten Personen ein um 59\% verbessertes Überleben.

Singal AG et al. Amer J Med 2017, online 14. Februar

\section{Antikörper beugt C. difficile vor}

Es seien dringend Therapien nötig, um das Rückfallrisiko bei einer C.-difficile-Infektion zu minimieren, so ein Forscherteam. Das Team hat nun sowohl einen Antikörper gegen das A-Clostridiumtoxin (Actoxumab) als auch gegen das B-Toxin (Bezlotoxumab) in zwei Studien geprüft. Primärer Endpunkt war die Rezidivrate nach drei Monaten. Mit Bezlotoxumab allein lag sie in Studie 1 bei 17\%, eine Kombitherapie brachte es auf $16 \%$, und in der Placebogruppe erkrankten $28 \%$ erneut. Der Erfolg von Actoxumab allein lag mit 26\% auf Placeboniveau. Ganz ähnlich die Resultate in Studie 2: Bezlotoxumab allein sowie eine Kombitherapie lagen mit $16 \%$ und $15 \%$ fast gleichauf, in der Placebogruppe kam es hingegen bei $26 \%$ zu einem Rezidiv.

Wilcox MHet al. N Engl J Med 2017;376:305-17

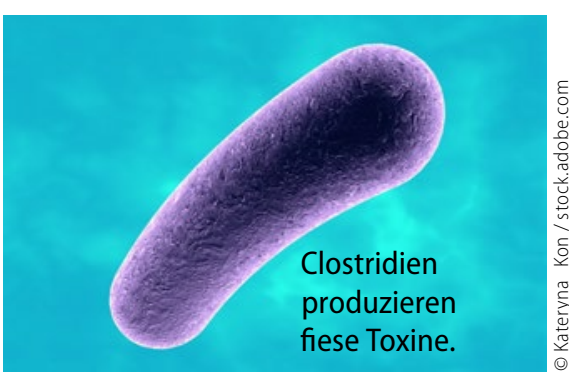

